Tese

\title{
MADISON E DAHL: DA REPÚBLICA À POLIARQUIA
}

\author{
José Alexandre Silva Junior, \\ Dalson Britto Figueiredo Filho, \\ Ranulfo Paranhos, \\ Gabriel Augusto Miranda Setti, \\ Willber Nascimento ${ }^{1}$
}

The worst thing that can happen to a good cause is not to be skillfully attacked, but to be ineptly defended.

Frederic Bastiat

All good government is and must be republican.

John Adams

\section{INTRODUÇÃO}

O pensamento político clássico exerceu influência sobre a formação e o desenvolvimento da teoria política contemporânea. Isso porque inúmeras questões que são cotidianamente debatidas nos diferentes departamentos de Ciência Política conservam, em sua essência, elementos que foram introduzidos pelos gregos. Além disso, guardadas as devidas proporções, muitos dos problemas que preocupavam Platão e Aristóteles podem ser facilmente encontrados em formas de projetos de lei dentro das

\footnotetext{
1 Universidade Federal de Alagoas. Contato: jasjunior2007@yahoo.com.br

Universidade Federal de Pernambuco. Contato: dalsonbritto@yahoo.com.br

Universidade Federal de Alagoas. Contato: ranulfoparanhos@me.com

Universidade Federal de Alagoas. Contato: gabrielsetti@gmail.com

Universidade Federal de Pernambuco. Contato: willbernascimento@outlook.com
} 


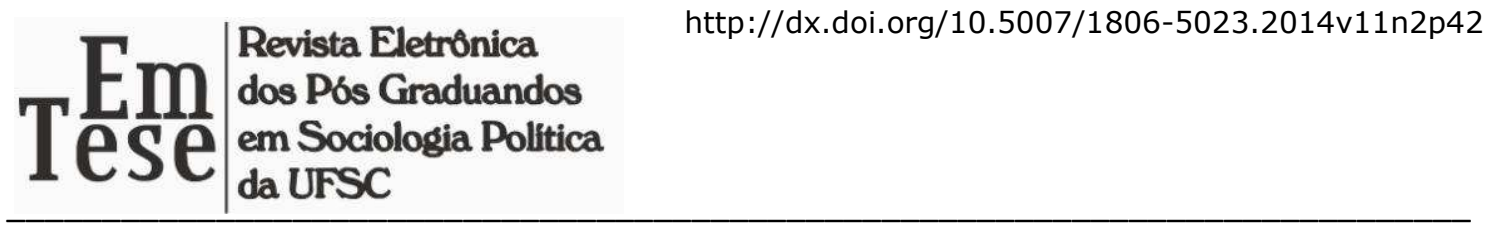

comissões no Congresso Nacional. Por exemplo, a representação, tema amplamente discutido por Rousseau e Stuart Mill, continua sendo não só um dos principais objetos de pesquisa da teoria política mais recente como também desperta uma variada gama de discussões normativas e positivas na Ciência Política contemporânea. Seguramente, é difícil estimar em que medida a influência dos clássicos se processou de forma direta ou indireta, explícita ou implicitamente, no entanto, é impossível negá-la.

Dentro desse espírito, esse trabalho procura sistematizar alguns elementos do pensamento de James Madison e Robert Dahl em perspectiva comparada. Especificamente, o foco repousa sobre as noções madisonianas de facções, separação de poderes e república, bem como sobre o conceito de poliarquia elaborado por Dahl. Esse trabalho tem como público alvo estudantes de graduação e pós-graduação em Ciência Política especificamente e, Ciências Humanas e Sociais de maneira geral.

Para executar o referido desenho de pesquisa, o artigo está dividido em quatro partes. A próxima seção discute a noção madisoniana de facção. Depois disso, o objetivo é analisar o conceito de separação de poderes. A terceira parte discute as noções de república e poliarquia a partir de Madison e Dahl, respectivamente. Por fim, a quarta seção apresenta as principais conclusões do presente trabalho.

\section{MADISON, PLURALISMO E FACÇÕES}

Nenhum outro país foi mais profundamente marcado pelo pluralismo do que os Estados Unidos. De acordo com Dahl (1956), os escritos de Madison influenciaram não só o desenvolvimento da democracia, mas também a difusão do pluralismo como ideal nos EUA ${ }^{2}$. Dahl, citado por Bobbio (1994), argumenta que o pluralismo pode ser pensando da seguinte forma:

Em lugar de um centro singular de poder soberano, devem existir muitos centros, mas nenhum deles deve ou pode ser inteiramente soberano. Na perspectiva do pluralismo norte-americano, o único soberano legítimo é o povo, mas o povo não deve nunca ser um soberano absoluto (...). A teoria e a prática do pluralismo norte-americano tendem a afirmar que a existência de uma multiplicidade de centros do poder, sem que nenhum deles seja

\footnotetext{
${ }^{2}$ Para uma análise detalhada do pensamento de Madison ver Yoho (1995).
} 


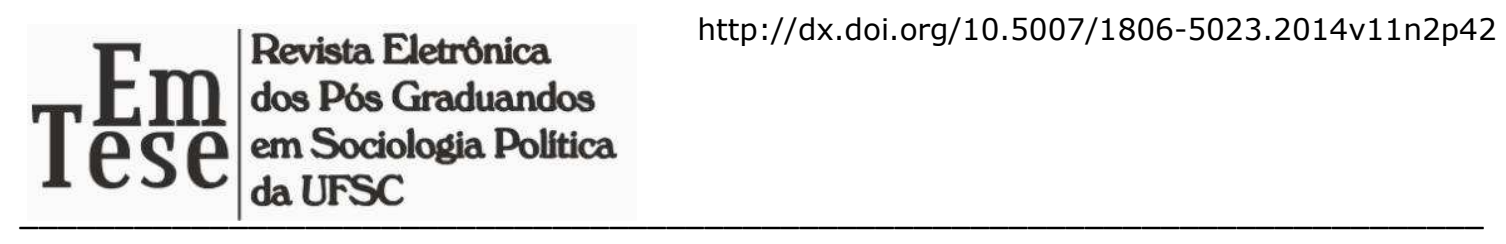

inteiramente soberano, ajuda a controlar o poder e a assegurar o consentimento de todos para a solução pacífica dos conflitos (BOBBIO, 1994, p. 15).

Dentro dessa concepção, a dispersão do poder tem um papel central. Antagonicamente à posição hobbesiana de poder centralizado e absoluto, o pluralismo apenas é possível se o poder for compartilhado. Isto porque, o centro analítico do pluralismo decorre da ideia de que como os diferentes grupos podem competir entre si pelas posições na estrutura do Estado, nenhum deles pode conseguir ser dominante, tornando, desse modo, o sistema equilibrado. Para os propósitos deste artigo, é interessante analisar o conceito de pluralismo vis-à-vis a ideia de facção. Para Madison (2003),

Entendo por facção uma reunião de cidadãos, quer formem a maioria ou a minoria do todo, uma vez que sejam unidos e dirigidos pelo impulso de uma paixão ou interesse contrário aos direitos dos outros cidadãos, ou ao interesse constante e geral da sociedade (MADISON, 2003, p. 60).

Ou seja, facção é um determinado agrupamento de indivíduos, que ora constitua minoria ora maioria, que aja no sentido de suprimir os direitos "naturais" de qualquer parte da coletividade. Tecnicamente, é improvável que a maioria dos cidadãos aja no sentido de ameaçar a promoção dos direitos da maioria dos indivíduos. Isso porque, logicamente, a maioria não pode oprimir a si própria. Todavia, nada impede que a maioria aja deliberadamente no intuito de oprimir os direitos da minoria. Por outro lado, uma minoria organizada pode tentar suprimir os direitos naturais da maioria. De acordo com Dahl (1956), Madison estava mais preocupado com a tirania da maioria do que no contrário.

Para Madison, a tirania da maioria consistia um problema maior que o da tirania da minoria. Para federalistas como Madison e Hamilton, a democracia antiga não possuía mecanismo que defendessem a propriedade das minorias. Portanto, um dos papéis da Republica era o de garantir a propriedade especificamente a partir da construção de mecanismos institucionais que impedissem que uma maioria sobrepujasse os direitos políticos e econômicos das minorias (VITULLO, 2009). Como bem salientou Dahl (1990), nesse aspecto as preocupações de Madison em relação à maioria foram 


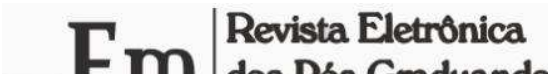

posta em "xeque" a partir dos elitistas, que ao contrário do que pensavam os "temerosos" da maioria tais como o próprio John Stuart Mill, Tocqueville, Madison e Hamilton, na prática quem sempre governou as sociedades democráticas foram alguma elite ${ }^{3}$.

De acordo com o próprio Madison, um dos principais objetivos do governo republicano é minimizar a influência das facções, identificando duas formas de evitar os efeitos negativos gerados pelo comportamento faccioso: "ou prevenir-lhe as causas, ou corrigir-lhe os efeitos" (MADISON, 2003, p. 60). Para combater as causas da facção, o autor sugere limitar a liberdade individual. Todavia, esse remédio, de acordo com Madison, "é pior do que o mal" (MADISON, 2003, p. 60). Seguindo a lógica madisoniana, portanto, a liberdade não pode ser suprimida com o objetivo de evitar o comportamento faccioso.

No que diz respeito em impor ou até mesmo incentivar que todos os cidadãos compartilhem as mesmas opiniões, paixões e interesses, Madison considera essa opção impraticável. Defende justamente o oposto: a pluralidade de opiniões e a heterogeneidade de paixões. E esses elementos apenas podem florescer em terras livres.

Em síntese, não é possível eliminar as causas das facções. Nas palavras de Madison: "concluamos que não é possível prevenir todas as causas de facções e que não resta outro remédio que de corrigir-lhes os efeitos (MADISON, 2003, p. 63). Nesse sentido, o autor argumenta em favor da formação de um governo que seja capaz de diminuir o alcance dos efeitos nocivos do "espírito faccionista". Essa construção vai depender em larga medida do desenho institucional. Esse é um dos legados mais importantes deixados pelos Federalistas: instituições importam ${ }^{4}$.

Ratificando essa visão, Dahl (1956) argumenta que uma das proposições fundamentais do pensamento madisoniano pode ser sintetizada na seguinte hipótese: "na ausência de controles externos, qualquer indivíduo ou grupo de indivíduos, tiranizará os demais" (DAHL, 1956, p. 14). Por sua vez, a concentração dos poderes é uma das maneiras de neutralizar o efeito dos controles externos. Logo, a separação dos

\footnotetext{
${ }^{3}$ Para maiores interessados nesse argumento, ver Dahl (1990). Acerca das elites políticas ver os capítulos concernentes à Mosca, Pareto e Michels em Souza (1954). Para um comentário acerca do pensamento desses três ver Perissinoto (2009).

${ }^{4}$ Outro componente central para evitar o comportamento faccioso é a extensão territorial da república. Isso porque um grande território comportaria uma maior quantidade de diferentes interesses, dificultando assim, a aglutinação de interesses comuns de caráter opressivo.
} 
poderes é vital para evitar a própria dissolução dos controles externos, o que por sua vez é um fator decisivo para que nenhum indivíduo ou grupo de indivíduos tiranize os seus semelhantes.

\title{
3. SEPARAÇÃO DOS PODERES, CONTROLES E TIRANIA ${ }^{5}$
}

Para compreender porque a grande maioria dos governos representativos adota um arranjo institucional que separa os poderes, é necessário entender a origem desse princípio. Historicamente, a preocupação com a divisão de poderes remonta à Grécia Antiga (nesse caso se tratava mais dos princípios de divisão de prerrogativas do que separação de poderes propriamente dito $)^{6}$ e tinha como principal objetivo evitar a tirania. Para Aristóteles:

Os vários grupos ou classes sociais participam do exercício do poder político, ou aquela em que o exercício da soberania ou o governo, em vez de estar nas mãos de uma única parte constitutiva da sociedade, é comum a todas. Contrapõem-se-lhe, portando, as constituições puras em que apenas um grupo ou classe social detém o poder político (apud PIÇARRA, 1989, p. 3233).

Locke também refletiu sobre a importância de um tipo de separação dos poderes. Inegavelmente, para Locke, o Legislativo é o poder supremo. Registre-se,

\begin{abstract}
Esse poder legislativo não é somente o poder supremo da comunidade, mas sagrado e inalterável nas mãos em que a comunidade uma vez o tenha colocado; nem pode qualquer edito de quem quer que seja, concebido por qualquer maneira ou apoiado por qualquer poder que seja, ter a força e a obrigação de uma lei se não tiver a sanção do legislativo escolhido e nomeado pelo público; porque, sem isto, a lei não teria o que é absolutamente necessário a sua natureza de lei: o consentimento da sociedade, sobre qual
\end{abstract}

\footnotetext{
${ }^{5}$ No Brasil, a separação de poderes está devidamente positivada pelo artigo $2^{\circ}$ da Constituição Federal, leia-se: São Poderes da União, independentes e harmônicos entre si, o Legislativo, o Executivo e o Judiciário (art. $2^{\circ}, \mathrm{CF} 88$ ).

${ }^{6}$ De certo, pode parecer existir um anacronismo na utilização do termo "divisão de poderes" para o período anterior a Montesquieu. Desse modo, salientamos que quando utilizamos o termo fazendo referência a períodos anteriores ao ocidente moderno, fazemos referências aos princípios que nortearam a construção dos modelos de separação dos poderes a partir de Montesquieu. Agrademos ao "parecerista" anônimo do artigo pela atenção demonstrada a essa questão.
} 


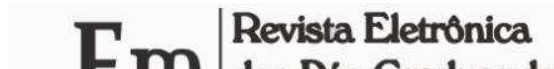

ninguém tem o poder de fazer leis senão pelo próprio consentimento daquela e pela autoridade dela recebida (LOCKE, 2006, p. 100-101).

A concepção lockeana, todavia, pressupõe que independentemente da forma de governo e do "desenho institucional", a principal finalidade de qualquer governo é garantir a conservação da propriedade. De acordo Madison, o governo não foi menos instituído para defender a pessoa dos cidadãos do que para defender a sua propriedade, e, portanto, uma e outra coisa devem ser igualmente representadas por aqueles que exercem as funções do governo. Logo, a separação dos poderes deverá ser elaborada tendo como principal meta conservar a propriedade. Aqui é possível identificar a relação mais íntima dos Federalistas com o liberalismo. O objetivo final é implementar um governo limitado que garanta efetivamente o livre desenvolvimento das faculdades mentais e econômicas dos indivíduos.

Objetivamente, é possível identificar dois critérios para separar os poderes em seu pensamento: 1) a natureza humana e 2) a natureza da função. A natureza humana tende a abusar do poder e uma forma de evitar esses abusos ou pelo menos reduzir a sua intensidade é a separação dos poderes. Dessa forma, é preciso compartilhar o poder no sentido de enfraquecê-lo. Uma concepção defendida por Hamilton e compartilhada por Madison é a de que os homens são "ambiciosos, vingativos e rapaces". Pensar de modo diferente, "seria ignorar o curso uniforme dos acontecimentos humanos e desafiar a experiência acumulada ao longo dos séculos" (HAMILTON, 2006, p. 249). Dessa forma, os mecanismos de controle serão elaborados no sentido de controlar a propensão humana ao abuso do poder.

No que diz respeito à natureza da função, Madison considera que a separação de poderes é um elemento essencial à liberdade, argumentando que se a Constituição tentar promover ou até mesmo favorecer, direta ou indiretamente, o acúmulo de poder, ela deve ser sumariamente rejeitada ${ }^{7}$.

\footnotetext{
${ }^{7}$ Para Madison, para manter a separação dos poderes, que todos (a exemplo de Stuart Mill, Tocquevile e Constant assentam ser essencial à manutenção da liberdade, é de toda necessidade que cada um deles tenha uma vontade própria; e, por consequiência, que seja organizado de tal modo, que aqueles que o exercitam tenham a menor influência possível na nomeação dos depositários dos outros poderes (...) é necessário que as nomeações para as supremas magistraturas legislativas saiam do povo, que é a fonte primitiva de toda a autoridade, por meio de canais que não tenham entre si a mínima comunicação" (MADISON, 2003, p. 317).
} 


\section{Tese

De acordo com Dahl (1956), Madison estava muito preocupado com a possibilidade da tirania ser exercida por parte do Legislativo. De acordo com Madison, não se exige a separação absoluta dos poderes como mecanismo para evitar a tirania. Ele exemplifica com a carta constitucional de New Hampshire para ilustrar o seu argumento de que não há uma separação total dos poderes. O problema, segundo Madison, é de o poder exercer completamente ou demasiadamente as funções do outro. Em outras palavras, deve-se procurar evitar não o contato entre os poderes, mas a ingerência sistemática de um poder sobre as atribuições do outro.

No entanto, é a aversão à tirania legislativa que ocupa maior atenção de Madison. Dessa forma, a ideia era consolidar a separação dos poderes (formular um arranjo institucional) que pudesse minimizar a supremacia do Legislativo frente aos demais poderes. O objetivo é conferir mais equilíbrio à relação entre os poderes, almejando, nesse sentido, o fortalecimento do Executivo. É possível identificar nos próprios artigos dos Federalistas uma tendência ao enfraquecimento do Legislativo em detrimento do fortalecimento do Executivo ${ }^{8}$.

Claramente, para que o controle mútuo seja efetivamente exercido é necessário o contato entre os poderes, e não seu isolamento. É justamente isso que Madison defende: um poder com capacidade de fiscalizar o outro, evitando a concentração plena de poderes na mesma mão. Dada a dupla tendência à usurpação e à expansão que o poder possui, não é suficiente apenas prescrever constitucionalmente os seus limites, é preciso mais do que isso.

É necessário colocar "a ambição contra a ambição" e atrelar os interesses humanos às obrigações dos cargos governamentais, de modo que não haja transgressão sem punição. Em suma, a "rivalidade de interesses" é o segredo de todos os negócios humanos, privados ou públicos. E essa rivalidade se demonstra especialmente

\footnotetext{
${ }^{8}$ Para Madison, o problema é que, nos governos republicanos, o poder legislativo tende necessariamente a predominar, e não é possível dar a cada um dos outros poderes meios suficientes para a sua própria defesa. O único recurso consiste em dividir a legislatura em muitas frações e em desligá-las uma das outras, já pela diferente maneira de elegê-las, já pela diversidade de seus princípios de ação, tanto quanto o permite a natureza das suas funções comuns e a dependência comum com que elas se acham da sociedade. Mas este mesmo meio ainda não basta para evitar todo o perigo das usurpações. Se o excesso de influência do corpo legislativo exige que ele seja assim dividido, a fraqueza do poder executivo, pela sua parte, pede que seja fortificado. O veto absoluto é, a primeira vista, a arma mais natural que pode darse ao poder executivo para que se defenda: mas o uso que ele pode fazer dela pode ser perigoso e mesmo insuficiente (MADISON, 2003, p. 318-319).
} 


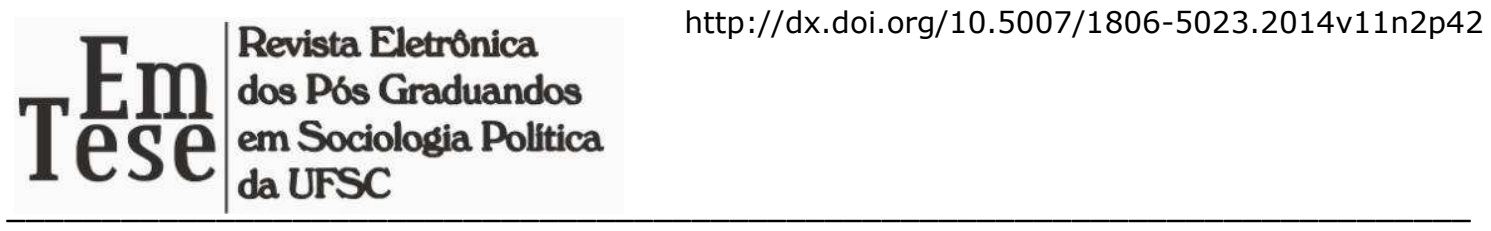

importante durante a distribuição do poder, quando a principal meta é garantir que o mesmo (o poder), seja amplamente compartilhado, de tal modo que um possa exercer controle sobre o outro: "que o interesse privado de cada indivíduo seja uma sentinela dos direitos públicos" (MADISON, 2003, p. 318).

Por fim, é possível afirmar que Locke (de um modo mais conceitual), Monstesquieu e os Federalistas são importantes referências no que diz respeito à separação de poderes. Cada um deles, com suas particularidades e inseridos em diferentes contextos históricos, refletiram sobre um problema que além de ocupar a atenção da Ciência Política contemporânea é absolutamente importante para compreender como funciona grande parte dos sistemas políticos atuais.

\section{REPÚBLICA, DEMOCRACIA E POLIARQUIA}

Dahl (1956) argumenta que a definição de democracia no contexto histórico em que Madison estava inserido se aproximava muito mais de um igualitarismo radical e/ou da noção de democracia direta do que qualquer outra coisa. Dessa forma, Madison se opunha claramente a implementação de uma forma de governo que se identificasse com esses conceitos. Por exemplo, para Madison, o espírito faccionista é inerente ao governo democrático (democracia direta grega $)^{9}$.

De acordo com Dahl (1956), a noção de república desenvolvida por Madison se aproxima fortemente da noção mais contemporânea de democracia representativa. Dentro do pensamento madisoniano, uma república é um governo em que: "todos os poderes procedem direta ou indiretamente do povo e cujos administradores não gozam senão de poder temporário cada, a árbitro do povo ou enquanto bem se portarem" (MADISON, 2003, p. 237).

Fica claro que Madison considera o governo republicano como a única alternativa possível para os desejos de uma nação livre. Ele apresenta exemplos históricos de outros países que não podem ser efetivamente considerados como

\footnotetext{
${ }^{9}$ Para Madison, é impossível ler a história das pequenas repúblicas da Grécia e da Itália sem sentir horror ou aversão diante das confusões que continuamente as agitavam e da rápida sucessão de revoluções através das quais se mantinham num estado de constante oscilação entre os extremos da tirania e da anarquia. Quando ocorriam períodos ocasionais de tranquilidade, apenas serviam como contrastes de curta duração das violentas tempestades que se sucediam” (in: Os clássicos da Política, 2006: 249).
} 


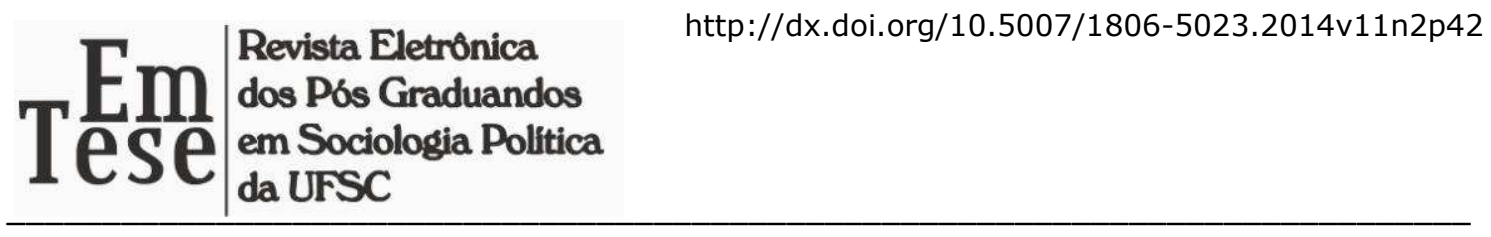

governos republicanos já que não conservam os princípios e a essência. Não basta ser um governo republicano de direito, é necessário sê-lo de fato. Em síntese, Madison afirma que todos esses exemplos (...) "mostram a extrema inexatidão com que a palavra república tem sido empregada nas discussões políticas" (MADISON, 2003, p. 237). Analiticamente, Madison distingue o conceito de república da noção de democracia a partir de dois pontos centrais. Em primeiro lugar, a república apresenta maior extensão territorial e maior quantidade de cidadãos. Como salientado por Dahl (2001), o tamanho da unidade geográfica consistia em um dos maiores problemas da democracia antiga. $\mathrm{O}$ segundo ponto de diferença consiste, segundo Madison, na condição de que os poderes na república são delegados a um pequeno número de indivíduos escolhidos pelo povo (MADISON, 2003, p. 64). Para Madison essa segunda característica aumenta o espírito público e garantirá que as decisões tomadas sejam as melhores para o bem da nação. Em suas palavras:

\begin{abstract}
A república aparta-se da democracia em dois pontos essenciais; não só a primeira é mais vasta e muito maior o número de cidadãos, mas os poderes são nela delegados a um pequeno número de indivíduos que o povo escolhe. $\mathrm{O}$ efeito desta segunda diferença é de depurar e de aumentar o espírito público, fazendo-o passar [por] um corpo escolhido de cidadãos, cuja prudência saberá distinguir o verdadeiro interesse da sua pátria e que, pelo seu patriotismo e amor da justiça, estarão mais longe de o sacrificar a considerações momentâneas ou parciais. Em um tal governo é mais possível que a vontade pública, expressa pelos representantes do povo, esteja [mais] em harmonia com o interesse público do que no caso de ser ela expressa pelo povo mesmo, reunido para este fim (MADISON, 2003, p. 64).
\end{abstract}

Segundo Vitullo (2009), o federalista Hamilton, também defendia a distinção entre república e democracia. Hamilton observa que a superioridade da república se tornava mais marcante principalmente pelo fato de que o poder político se realizava por meio da representação evitando assim os grandes problemas oriundos da realização de assembleias, que para ele expressava mais tumultos que tomada de decisões organizadas. Além de sua tendência à manipulação, intriga e demagogias (VITULLO, 2009).

Por mais paradoxal que possa parecer à primeira vista, Madison defende que “num tal governo é mais possível que a vontade pública, expressa pelos representantes do povo, esteja em harmonia com o interesse público do que no caso de ser ela expressa 


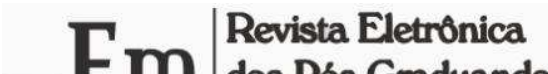

pelo próprio povo" (MADISON, 2003, p. 64). Com efeito, algum crítico poderia argumentar que Madison, ao considerar que os representantes agirão fielmente de acordo com os interesses de seus eleitores melhor do que eles próprios, não considera o risco de desvio de representação ${ }^{10}$.

Ao se comparar a definição de república de Madison e o conceito de poliarquia de Dahl (1970), algum analista poderia argumentar que o segundo incorpora, com mais sofisticação e refinamento, as propriedades do primeiro. Para Dahl (1971), as "poliarquias são regimes que foram substancialmente popularizados e liberalizados, isto é, fortemente inclusivos e amplamente abertos à contestação pública" (DAHL, 1971, p. $32)$.

Com efeito, as poliarquias são sistemas onde a escolha dos representantes é feita pelo povo e sua rotatividade é definida constitucionalmente. As regras do jogo são formuladas de tal sorte que o poder deriva do povo, os árbitros do poder são escolhidos pelo povo e possuem mandatos temporalmente regulados. Nesse sentido, é possível afirmar que quando Madison analisa em que medida o plano da Convenção reflete ou não os princípios republicanos, ele estabelece, ainda que de forma primitiva, a base dos eixos para se pensar a poliarquia de Dahl (inclusividade e contestação pública) ${ }^{11}$.

Outro ponto que aproxima esses autores é o esforço teórico comum no sentido de separar o que é uma verdadeira república, de sua versão "pirata". Como foi anteriormente argumentado, Madison se preocupou em distinguir o conceito de república da noção de democracia direta. Dahl, por sua vez, abandonou o conceito de democracia em função da noção de poliarquia. Inegavelmente, o conceito de democracia é um dos termos mais polissêmicos da teoria política (democracia direta, representativa, deliberativa, participativa, elitista, de alta intensidade, minimalista/procedimental, entre outros). Nesse sentido, tanto Madison quanto Dahl

\footnotetext{
${ }^{10}$ Todavia, esse argumento não se sustenta. Isso porque o próprio Madison reconhece que em alguns casos (...) "homens de caráter faccioso, cheios de prejuízos, filhos de circunstâncias locais e de projetos sinistros, por intriga, por corrupção e por outros meios ainda, obter os votos do povo e atraiçoar-lhe depois os interesses. Reduz-se, pois, a questão em saber se a grandeza ou pequenez das repúblicas é mais favorável à eleição dos melhores defensores do bem público: duas considerações sem resposta fazem que a decisão seja a favor da primeira" (MADISON, 2003, p. 64).

${ }^{11}$ De maneira geral isso é compreensível, quando se assume que Dahl toma as instituições políticas norteamericanas como um modelo inicial de sua teorização. Agradecemos, novamente ao parecerista que avaliou o artigo por essa ponderação.
} 


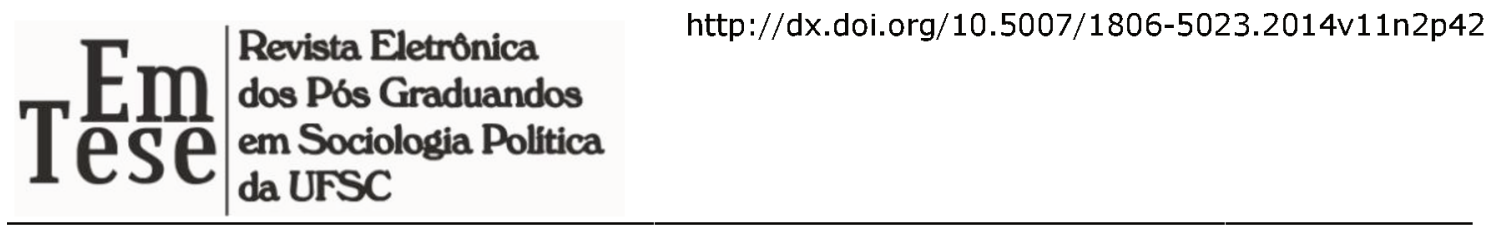

oferecem importantes ferramentas analíticas para se pensar mais sistematicamente a democracia.

Para operacionalizar a ideia de poliarquia, Dahl (1971) identifica oito variáveis: (1) Liberdade de formar e aderir a organizações; (2) Liberdade de expressão; (3) Direito de voto; (4) Elegibilidade para cargos públicos; (5) Direito de líderes políticos disputarem apoio; (6) Fontes alternativas de informação; (7) Eleições livres e idôneas; e (8) Instituições para fazer com que as políticas governamentais dependam de eleições e de outras manifestações de preferência. Essas oito garantias são reduzidas a dois fatores: a) contestação e b) inclusividade. Sendo que quanto maior for o grau de contestabilidade política e inclusividade mais próximo o regime encontra-se da poliarquia. A figura abaixo é bastante esclarecedora:

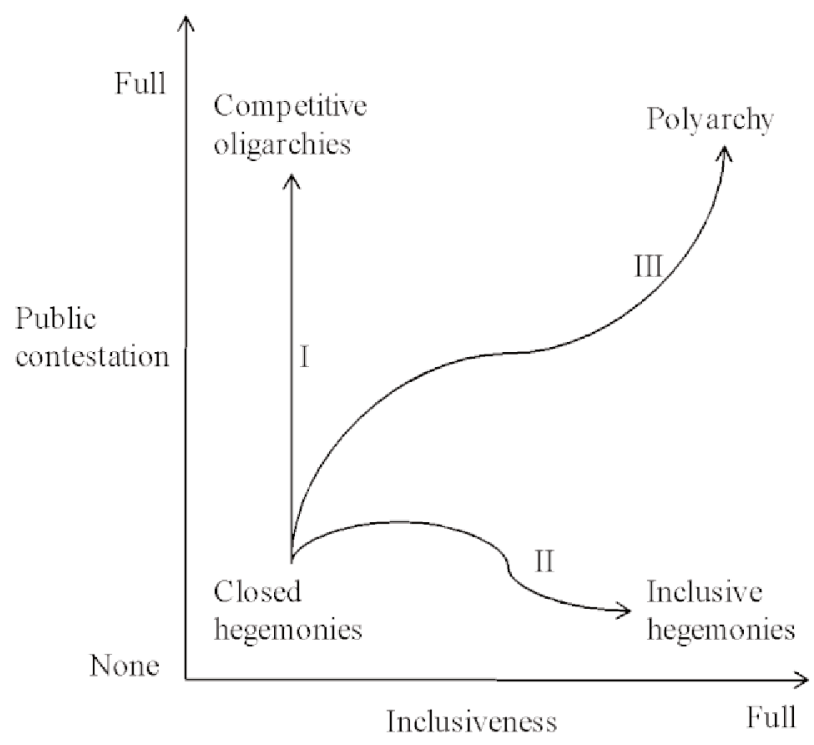

Fonte: Dahl (1971).

Na terminologia de Dahl, nos regimes classificados como Hegemonias fechadas (Closed hegemonies) tanto a inclusividade quanto a contestação encontram-se fracamente desenvolvidas. Os regimes que apresentam alta inclusividade, mas que ainda não desenvolveram um sistema de competição e institucionalização das regras do jogo são definidos como Hegemonias inclusivas (Inclusive hegemonies). Os regimes que apresentam alta contestação, mas que ainda não permitem a participação popular no processo de seleção dos representantes podem ser caracterizados, segundo Dahl, como Oligarquias competitivas (Competitive olygarchies). Finalmente, sistemas fortemente 


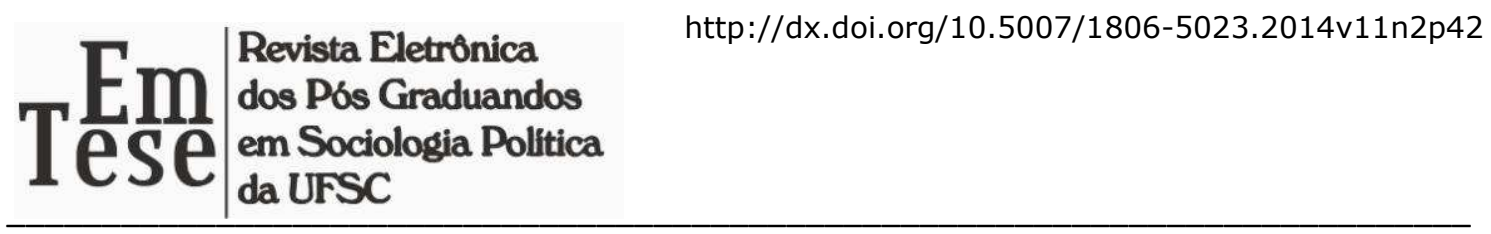

liberalizados e inclusivos são denominados de poliarquias. A poliarquia é, nesse sentido, o sistema de governo real mais próximo do modelo democrático ideal. Na visão de Madison, por sua vez, quanto maior for o sufrágio (inclusividade) maior será o descolamento dos representantes frente aos interesses particulares dos representados ${ }^{12}$.

No que diz respeito à contestação (eixo Y), ela está diretamente ligada à ideia de representação. Como escreveu Hamilton, sobre o efeito da representação,

(...) refinar e ampliar as opiniões do povo, fazendo-as passar pelo crivo de um corpo de cidadãos selecionados, cuja sabedoria pode melhor discernir o verdadeiro interesse de seu país e cujo patriotismo e amor à justiça fazem deles cidadãos menos suscetíveis a sacrificar esse interesse por considerações efêmeras e parciais. Em um sistema desse tipo, é provável que a vontade popular, expressa pelos representantes do povo, venha a ser mais compatível com o bem público do que se fosse manifesta pelo próprio povo, reunido para esse fim" (HAMILTON, 1961, p. 82: in MANIN, 1995).

O sistema representativo, ao se tornar gradativamente mais inclusivo e institucionalizado, passa a ser, dentro dessa visão, fortemente responsivo em relação às demandas dos cidadãos, agora eleitores. De forma geral, portanto, fica evidente que um dos principais objetivos perseguidos pelos Federalistas é implementar um sistema amplamente representativo que seja capaz de selecionar os indivíduos mais aptos a resistir às paixões desordenadas e aos equívocos que podem tomar conta do povo. Claramente, o representante não é, e não deve ser uma marionete do povo, segundo os Federalistas.

\section{CONSIDERAÇÕES FINAIS}

Esse trabalho concentrou esforços analíticos em discutir três importantes conceitos da obra de James Madison: facções, separação de poderes e república. Não se

\footnotetext{
${ }^{12}$ No original, "Como cada representante será escolhido por um número maior de cidadãos nas grandes do que nas pequenas repúblicas, será mais difícil para os candidatos sem méritos utilizar com êxito artifícios desonestos, que tantas vezes têm dado a vitória nas eleições; e os sufrágios do povo, sendo mais livres, terão maior probabilidade de se concentrarem sobre pessoas que possuam méritos mais atraentes e personalidades mais firmes e propagadoras" (MADISON, 2003, p. 65).
} 


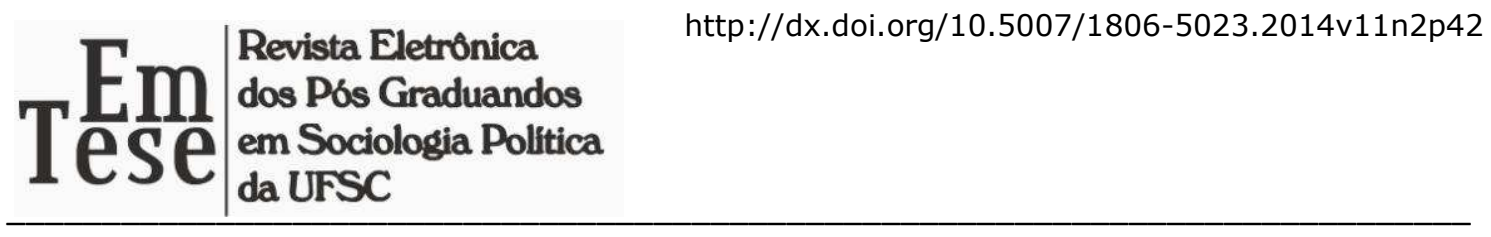

pretendeu aqui explorar todos os pontos relevantes contidos nos Federalistas. Isso seria um trabalho demasiado longo e delicado. A ideia central foi estabelecer, sempre que possível, uma perspectiva analítica comparada com outros autores clássicos, notadamente Locke e Montesquieu, por um lado, e com Dahl por outro. A partir desta análise, foi possível notar que o pensamento político contemporâneo é fortemente tributário das teorizações clássicas. De certo modo, observa-se que ainda na contemporaneidade são discutidos temas que preocupavam os gregos, na Antiguidade e os contratualistas, na Idade Moderna, por exemplo. Dessa forma, nosso principal objetivo foi argumentar em favor da influência que a teoria política clássica exerceu sobre o desenvolvimento da teoria e da Ciência Política contemporânea. Isso porque algumas vezes há uma tendência de relegar os autores clássicos ao segundo plano.

De modo mais direto, o debate acerca da separação de atribuições na estrutura do Estado, bem como sua formulação ocidental moderna, a divisão de poderes, é um tema que remonta à Antiguidade, à Idade Moderna e aos contemporâneos. Além disso, o debate federalista, principalmente alguns argumentos de Madison - tais como organizações políticas (facções), diferenciação entre conceitos república/democracia, o tamanho das unidades políticas e representação política - foram extremamente importantes para a formulação do conceito de Poliarquia de Robert Dahl.

É possível também identificar que, ao longo do desenvolvimento do pensamento político (clássico e contemporâneo), determinadas questões, que apesar de terem sido analisadas sob perspectivas diferentes e até mesmo antagônicas, conservam, em maior ou menor grau, uma essência comum. Esse é o fator central que possibilita a continuidade das discussões e a cumulatividade do conhecimento. Mais do que isso, é justamente a contribuição dos autores clássicos que permite que a teoria política contemporânea seja capaz de tentar oferecer explicações mais robustas aos "novos" problemas enfrentados pela disciplina. Dessa forma, negar a importância e a relevância dos autores clássicos para compreender os problemas contemporâneos é negar a própria teoria política. 


\section{REFERÊNCIAS}

ARISTÓTELES. A política. Tradução de Roberto Leal Ferreira. São Paulo: Martins Fontes, 1998.

BOBBIO, Norberto. A teoria das formas de governo. 10. ed. Tradução de Sérgio Bath. Brasília: UnB, 2001.

DAHL, Robert. A Preface to Democratic Theory, Chicago, University of Chicago Press, 1956.

1971.

Poliarchy: Participation and Opposition, New Haven, Yale University Press,

. Um prefácio à democracia econômica. Trad. de Ruy Jungmann. Rio de Janeiro: Zahar, 1990.

. Sobre a Democracia. Brasília: Editora da UnB, 2001.

HAMILTON, Alexander; JAY, John; MADISON, James. O federalista. Trad. Hiltomar Martins Oliveira. Belo Horizonte: Líder, 2003.

MADISON, James; HAMILTON, Alexander; JAY, John. O federalista. Trad. Hiltomar Martins Oliveira. Belo Horizonte: Líder, 2003.

MANIN, Bernard. "As metamorfoses do Governo Representativo". Revista Brasileira de Ciências Sociais, n. ${ }^{\circ}$ 29, ano 10, outubro 1995.

MAQUIAVEL, Nicolau. O Príncipe. 2a ed. São Paulo, Martins Fontes, 1996.

MICHELS, Robert. “A Lei de Ferro da Oligarquia”. In: SOUZA, A. (org.). Sociologia Política. Rio de Janeiro: Zahar Editores, 1954.

. “A Base Conservadora da Organização". In: SOUZA, A. (org.). Sociologia Política. Rio de Janeiro: Zahar Editores, 1954. 
MONTESQUIEU, Charles-Louis S. de. Do espírito das leis. 2 a ed. São Paulo,Abril Cultural, 1979.

MOSCA, Gaetano. "A Classe Dirigente". In: SOUZA, A. (org.). Sociologia Política. Rio de Janeiro: Zahar Editores, 1954.

PARETO, Vilfredo. "As Elites e o uso da Força na Sociedade". In: SOUZA, A. (org.). Sociologia Política. Rio de Janeiro: Zahar Editores, 1954.

PERISSINOTTO, Renato. As elites políticas: questões de teoria e método. Curitiba: Ibepex, 2009.

PIÇARRA, Nuno. A separação dos poderes como doutrina e princípio constitucional: um contributo para o estudo das suas origens e evolução. Coimbra: Coimbra, 1989, 2009.

ROUSSEAU, Jean.-Jaques. Contrato social. Coleção Os Pensadores. São Paulo: Abril, 1978a.

VITULLO, Gabriel. Representação política e democracia representativa são expressões inseparáveis? Elementos para uma teoria democrática pós-representativa e pós-liberal. Revista Brasileira de Ciência Política, no 2. Brasília, julho-dezembro de 2009, pp. 271301.

WELFFORT, Francisco. Os Clássicos da Política. Editora Ática, 2006. 


\title{
MADISON E DAHL: DA REPÚBLICA À POLIARQUIA
}

Resumo: Qual é a relação entre as teorias política clássica e contemporânea? O principal objetivo desse trabalho é responder a referida questão. Em termos metodológicos, examinam-se alguns conceitos analisados por James Madison e Robert Dahl em perspectiva comparada. Em particular, o foco repousa sobre as noções madisonianas de facção, separação de poderes e república e sobre o conceito de poliarquia proposto por Dahl. Dessa maneira, descrevemos a contínua influência de certos aspectos próprios da teoria política clássica no modo como a teoria contemporânea lida com o tema. Concluímos que a contribuição dos autores clássicos permite que a teoria política contemporânea seja capaz de tentar oferecer explicações mais robustas aos "novos" problemas enfrentados pela disciplina.

Palavras-chaves: Facção. Separação de poderes. República. Poliarquia.

\section{MADISON AND DAHL: OD THE REPUBLIC TO POLYARCHY}

\begin{abstract}
What is the relationship between classical and contemporary political theory? The principal aim of this paper is to answer this question. On methodological grounds, we examine some concepts analyzed by James Madison and Robert Dahl in a comparative perspective. In particular, the focus relies on madisonian notions of factions, separation of powers and republic and on the concept of polyarchy proposed by Dahl. Thus, we describe the continuing influence of certain specific aspects of classical political theory in the way contemporary theory deals with the theme. We conclude that the contribution of the classical authors allows the contemporary political theory to be able to try and offer more robust explanations to the "new" problems faced by the discipline.
\end{abstract}

Keywords: Faction. Separation of powers. Republic. Polyarchy.

Recebido em: 11 de agosto de 2014

Aceito para publicação em: 19 de setembro de 2014 